\title{
MANEJO QUÍMICO DE Eichhornia crassipes E Brachiaria subquadripara COM DIQUAT EM CONDIÇÕES DE RESERVATÓRIO ${ }^{1}$
}

\author{
Chemical Control of Eichhornia crassipes and Brachiaria subquadripara with Diquat under \\ Reservoir Conditions
}

\begin{abstract}
MARTINS, D. ${ }^{2}$, VELINI, E.D. ${ }^{2}$, COSTA, N.V. ${ }^{3}$, CARDOSO, L.A. ${ }^{4}$ e SOUZA, G.S.F. ${ }^{5}$
RESUMO - Este trabalho teve como objetivo avaliar a eficiência do herbicida diquat no controle de plantas de Eichhornia crassipes e Brachiaria subquadripara em condições de reservatório. As parcelas experimentais apresentavam $650 \mathrm{~m}^{2}$ e foram delimitadas e posicionadas por redes de pesca nas margens do reservatório de Salto Grande, Americana-SP. Os tratamentos testados foram: herbicida diquat aplicado na formulação Reward, nas doses de $960 \mathrm{~g}$ i.a. ha-1 (duas aplicações de $480 \mathrm{~g}$, com intervalo de 15 dias), 960 g i.a. ha ${ }^{-1}$ (aplicação única), $1.920 \mathrm{~g}$ i.a. ha ${ }^{-1}$ (duas aplicações de $960 \mathrm{~g}$, com intervalo de 15 dias), além de uma testemunha sem aplicação do herbicida. Para monitoramento das concentrações de diquat, foram coletadas amostras de água antes da aplicação do herbicida e 1, 2, 4, 7, 14 e 28 dias após aplicação (DAA) na área experimental e na montante e jusante da barragem. A análise da eficiência do diquat foi realizada através de avaliações visuais de controle no periodo $(1,2,4,7,14,21 \mathrm{e}$ 28 DAA do herbicida) e aos dois dias após a segunda aplicação. O herbicida diquat mostrouse eficiente no controle das plantas de E. crassipes, independentemente da dose e do manejo de aplicação, e seu efeito sobre as plantas de B. subquadripara foi temporário.
\end{abstract}

Palavras-chave: aguapé, herbicida, planta aquática, planta daninha, tanner-grass.

ABSTRACT - This study aimed to evaluate the efficacy of the herbicide diquat in controlling Eichhornia crassipes and Brachiaria subquadripara plants under reservoir conditions. The experimental plots were $650 \mathrm{~m}^{2}$, delimited and positioned on the shores of the Salto Grande Reservoir in Americana-SP, Brazil, using fishing nets. The treatments consisted of herbicide diquat, applied as the REWARD commercial formulation at $960 \mathrm{~g}$ a.i. ha $\mathrm{h}^{-1}$ (two applications at $480 \mathrm{~g}$, at an interval of 15 days), $960 \mathrm{~g}$ a.i. ha $\mathrm{g}^{-1}$ (single application), $1.920 \mathrm{~g}$ a.i. ha-1 (two applications at $960 \mathrm{~g}$, at an interval of 15 days) and a control without herbicide application. The concentrations of diquat in water were monitored before herbicide application and 1, 2, 4, 7, 14 and 28 days after application (DAA), in the experimental area and downstream and upstream. Diquat efficiency was evaluated through visual assessments of control at 1, 2, 4, 7, 14, 21 and 28 DAA of herbicide application and two days after the second application. Diquat showed excellent control of $\boldsymbol{E}$. crassipes, regardless of the dose tested and type of management, with its effect on $\boldsymbol{B}$. subquadripara plants being temporary.

Keywords: aquatic weed, herbicide, aquatic plant, weed, tanner-grass.

\section{INTRODUÇÃO}

A intervenção antrópica estabelecida de maneira não planejada sobre os diversos ecossistemas aquáticos - como a construção de reservatórios para fins hidrelétricos, fonte de água potável para a população urbana ou para irrigação de lavouras, manipulação dos níveis higrométricos desses reservatórios e o desmatamento das matas ciliares - promovem

Recebido para publicação em 14.1.2011 e na forma revisada em 18.2.2011

2 Professor Livre Docente, Dep. de Produção Vegetal, Universidade Estadual Paulista - FCA-UNESP, Caixa Postal 237, $18603-970$ Botucatu-SP, <secdamv@fca.unesp.br>; ${ }^{3}$ Professor Adjunto, UNIOESTE, Marechal Cândido Rondon-PR, $<$ neumarciove@hotmail.com>; ${ }^{4}$ Dr., Engo - Agr ${ }^{\circ}$., Consultor da FAO - Guiné Bissau, <leonildocardoso@hotmail.com>; ${ }^{5}$ Mestrando, FCA/UNESP, Caixa Postal 237, 18610-307 Botucatu-SP, <guisasso@hotmail.com>. 
uma série de alterações nas características químicas, físicas e bióticas dos corpos hídricos, levando às mudanças expressivas na comunidade biótica que os coloniza, incluindo expansão de populações de plantas aquáticas (Campos et al., 2010).

A ocorrência de plantas aquáticas em reservatórios brasileiros tem merecido destaque nos últimos anos, principalmente pelo potencial prejuízo que representa à geração de energia e consequente possibilidade de racionamento em grandes centros urbanos (Tanaka et al., 2002; Martins et al., 2003; Carvalho et al., 2005; Cavenaghi et al., 2005; Martins et al., 2008, 2009). Diversas espécies foram observadas nesses levantamentos; entre as principais encontram-se Eichhornia crassipes e Brachiaria subquadripara.

E. crassipes (aguapé) é considerada a pior planta daninha aquática do mundo, classificada como planta aquática flutuante livre, nativa do continente sul-americano e pertencente à família Pontederidaceae, que se reproduz por sementes e de forma vegetativa, via estolões (Kissmann, 1997; Lorenzi, 2000). Encontra-se amplamente distribuída nas regiões tropicais e subtropicais, devido à sua capacidade de reprodução e crescimento (Swarbrick, 1981). Verdadeiras ilhas de plantas de aguapé chegam até as grades de captação de água de usinas hidrelétricas, rompendo-as e interrompendo o funcionamento das turbinas.

B. subquadripara (tanner-grass) é uma espécie perene e estolonífera reproduz-se facilmente por meios vegetativos e produz poucas sementes, as quais têm baixa eficiência de reprodução (Roche et al., 1990; Kissmann, 1997; Lorenzi, 2000). Apresentase como importante invasora da cultura do arroz irrigado por inundação e, principalmente, de canais de irrigação e drenagem (Kissmann, 1997). Também é muito encontrada em grande quantidade nas margens de lagos e reservatórios utilizados para múltiplos usos da água, como geração de energia, recreação, pesca e navegação (Tanaka, 2002).

Os programas de manejo de plantas daninhas aquáticas devem abranger uma ampla gama de fatores científicos, operacionais, ambientais, econômicos e sociológicos para que tenham os resultados desejados. O controle de plantas daninhas aquáticas pode ser realizado utilizando-se métodos mecânico, químico, biológico e físico. O método ou conjunto de métodos a ser adotado é determinado pelos tipos de planta presentes, usos da água, recursos disponiveis e legislação.

Em outros países, como Estados Unidos, Canadá e Nova Zelândia, as plantas aquáticas vêm sendo estudadas há muitos anos, e diferentes métodos de controle, mecânicos, biológicos e químicos, são adotados. Dentro do controle químico, uma grande quantidade de herbicidas já foi testada, isoladamente ou de maneira associada a outras práticas, sendo selecionados aqueles em que o controle não acarreta prejuízos ao habitat natural dessas plantas ou mesmo a peixes e outros organismos aquáticos (Marchi et al., 2009), como, por exemplo, o diquat.

O diquat é um herbicida de contato, não seletivo, inibidor do fotossistema I e pertencente ao grupo químico dos bipiridílios; demonstra elevado potencial para uso em ambientes aquáticos no controle de plantas daninhas emersas e imersas, em razão da sua segurança sobre os organismos aquáticos, ser pouco atraído aos materiais lipídicos e possuir baixas taxas de bioconcentração (Lavorenti, 1996; Rodrigues \& Almeida, 2005).

Um exemplo flagrante do efeito nocivo das plantas aquáticas localiza-se nas proximidades de grandes centros urbanos, como São Paulo, Belo Horizonte, Rio de Janeiro e Recife. Em corpos d'água próximos a esses centros, plantas como E. crassipes e B. subquadripara, entre outras, predominam. Essas plantas causam problemas de procriação de mosquitos e de vetores de doenças humanas, impedem atividades de recreação e de pesca e proporcionam condições microaerofillicas com produção de substâncias de mau odor (Pitelli, 1998).

Este trabalho teve como objetivo avaliar a eficiência do herbicida diquat no controle de E. crassipes e B. subquadripara em condições de reservatório.

\section{MATERIAL E MÉTODOS}

O estudo foi realizado durante o ano de 2005 no reservatório de Salto Grande, 
pertencente à CPFL, no rio Atibaia, município de Americana-SP; as coordenadas geográficas da área de aplicação eram de 22K 0268997/ UTM 7486192 .

As parcelas experimentais tinham $650 \mathrm{~m}^{2}$, sendo elas delimitadas e posicionadas nas margens do reservatório através de redes de pesca. As parcelas continham as espécies de plantas aquáticas de ocorrência natural do local, como Pistia stratiotes, Salvinia auriculata, E. crassipes e B. subquadripara. Os tratamentos testados foram: herbicida diquat, aplicado na formulação comercial Reward, nas doses de 960 g i.a. ha ${ }^{-1}$ (duas aplicações de 480 g, com intervalo de 15 dias), 960 g i.a. ha ${ }^{-1}$ (aplicação única) e $1.920 \mathrm{~g}$ i.a. ha ${ }^{-1}$ (duas aplicações de $960 \mathrm{~g}$, com intervalo de 15 dias), e uma testemunha sem aplicação do herbicida.

As doses escolhidas foram baseadas em estudos realizados por Martins et al. (2002), em condições de caixas-d'água, no qual o produto mostrou-se eficiente no controle das plantas de E. crassipes, P. stratiotes e S. auriculata.

O herbicida foi aplicado em um volume de calda de $201 \mathrm{~L} \mathrm{ha}^{-1}$, por meio de uma barra de pulverização munida de pontas de pulverização modelo Teejet AI 11002, acoplada a um aerobarco, que dispunha de bomba de pistão acionada por motor a gasolina e reservatório com 200 litros de capacidade. O aerobarco apresentava, ainda, um sistema de navegação com GPS, barra de luzes e um variador de fluxo, que corrigia automaticamente a vazão de calda injetada em função da variação da velocidade da embarcação, garantindo assim uniformidade da concentração nas áreas experimentais. As parcelas experimentais ficaram distantes $20 \mathrm{~m}$ uma das outras.

Para o monitoramento das concentrações de diquat, foram coletadas amostras de água antes da aplicação do herbicida e 1, 2, 4, 7, 14 e 28 dias após aplicação (DAA) do diquat na área aplicada e na jusante da barragem de Salto Grande. As amostras de água foram obtidas ao longo de $40 \mathrm{~cm}$ da coluna de água.

Foram realizadas avaliações de controle somente das espécies que apresentavam quantidade e distribuição uniforme nas parcelas (E. crassipes e B. subquadripara) através da atribuição de notas visuais de controle e percentual $(1,2,4,7,14,21$ e 28 DAA do herbicida), por meio de uma escala percentual de notas, na qual zero representava nenhum controle e $100 \%$, o controle total das plantas (SBPD, 1995). Também, aos dois dias após a segunda aplicação foi realizada uma avaliação de controle, o que equivaleria a 17 dias após a primeira aplicação. Ressalta-se que, antes da aplicação dos tratamentos químicos, a massa seca dessas duas espécies de plantas aquáticas foi quantificada. Os valores médios obtidos nas avaliações de controle foram comparados pelo teste $t(p<0,01)$.

\section{RESULTADOS E DISCUSSÃO}

Independentemente de o herbicida diquat ser eficiente no controle de plantas como $P$. stratiotes e $S$. auriculata, como observado nos estudos de caixas-d'água realizados por Martins et al. (2002), essas espécies não ocorreram de maneira uniforme e em quantidade suficiente nas parcelas experimentais, para permitir uma avaliação adequada, bem como uma análise de variância consistente. As poucas plantas de ambas as espécies observadas na área experimental foram controladas de forma eficiente pelo herbicida. Notou-se também que, quando eslas estavam sob as plantas de aguapé, ocorreu o bloqueio dos jatos de pulverização pelas plantas mais altas, o que pode ser um fator determinante na deposição de calda em plantas de alface-d'água e salvínia, que convivem associadas com plantas de aguapé (Marchi et al., 2009).

Foi efetuado um levantamento da biomassa das duas principais espécies daninhas presentes na área experimental antes da aplicação dos tratamentos químicos; a massa seca de plantas de aguapé encontrada foi em média de $13,5 \mathrm{t} \mathrm{ha}^{-1}$, e para o tanner-grass, em média de 11,2 $\mathrm{t} \mathrm{ha}^{-1}$. De acordo com Perazza et al. (1985), durante o ano existem sete meses favoráveis ao melhor desenvolvimento e crescimento das plantas de aguapé, e a produtividade anual de biomassa pode atingir até $154 \mathrm{t} \mathrm{ha}^{-1}$, em condições ótimas. Domingos (2007), estudando colonizações de $B$. subquadripara, observou valores de massa seca de até $5,5 \mathrm{tha}^{-1}$ no periodo de chuvas e 4,19 tha $\mathrm{t}^{-1}$ no período de seca. Os resultados da massa seca das plantas após o encerramento do estudo não foram obtidos, 
pois houve rompimento das redes de amarração de duas parcelas, o que impossibilitou a coleta da massa resultante dos tratamentos testados.

$\mathrm{Na}$ Tabela 1 estão apresentados os resultados da porcentagem de controle de E. crassipes proporcionado por diferentes doses do herbicida diquat em diversos periodos de avaliação após a sua aplicação. Observa-se que, já no primeiro DAA, esse herbicida proporcionou sintomas de intoxicação às plantas de aguapé, independentemente da dose aplicada. Aos 2 DAA, os sintomas evoluíram em todos os tratamentos, mas somente aos 4 DAA atingiram niveis de controle considerados satisfatórios: entre 83,8 e $86,7 \%$. Os três tratamentos químicos mostraram-se muito semelhantes até esse momento, independentemente da dose aplicada, corroborando os estudos realizados em condições de caixas-d'água por Martins et al. (2002), que, ao avaliarem o mesmo herbicida e dosagens de 960 e 1.400 g i.a. ha ${ }^{-1}$, observaram médias de controle de 80 e $80,75 \%$, respectivamente, aos 5 DAA.

Na avaliação realizada aos 7 DAA, nota-se que todos os tratamentos químicos avaliados apresentaram ligeira redução das porcentagens de controle das plantas de aguapé, porém mantendo-se acima de $83 \%$; contudo, aos 14 DAA esses níveis de controle foram incrementados, atingindo valores próximos a $90 \%$. Esses resultados são muito semelhantes aos obtidos por Neves et al. (2002), que observaram aos 10 DAA médias de controle de 90\% das plantas de E. crassipes, promovidas pelo uso de diquat a $1,2 \mathrm{~kg} \mathrm{ha}^{-1}$ em caixas plásticas com 3,75 litros.

Com a segunda aplicação (sequencial) de diquat em dois dos três tratamentos químicos testados, as porcentagens de controle das plantas de aguapé aos 17 DAA, ou seja, dois dias após a segunda aplicação desses tratamentos, apresentaram-se excelentes, com exceção do tratamento com aplicação única de $960 \mathrm{~g} \mathrm{ha}^{-1}$, que se manteve abaixo de $90 \%$, porém considerado ainda eficiente.

Aos 21 e 28 DAA, o controle manteve-se nos níveis da avaliação anterior para os tratamentos com aplicações sequenciais; já o tratamento com $960 \mathrm{~g} \mathrm{ha}^{-1}$ de diquat aplicado em uma única época também passou a proporcionar um controle excelente, e todos os tratamentos atingiram controle em torno de $98 \%$ ao final das avaliações.

A aplicação sequencial da dose de $480+480 \mathrm{~g} \mathrm{ha}^{-1}$, em relação à dose única de $960 \mathrm{~g} \mathrm{ha}^{-1}$, traria benefícios quando ocorressem populações mistas, por exemplo, aguapé e alface-d'água, devido ao efeito guarda-chuva, mas os resultados encontrados confirmaram os obtidos em caixa-d'água por Martins et al. (2002), Neves et al. (2002) e Cardoso et al. (2003), em que o herbicida diquat controlou de forma eficaz as plantas da espécie $E$. crassipes. Outro fato observado refere-se ao aspecto das plantas após a sua morte, pois estas ficaram secas e íntegras sob a água e não imergiram no local controlado, ficando flutuando na área, o que pode possibilitar ao vento dispersar as plantas pelo corpo hídrico, minimizando os efeitos da decomposição de grandes massas de plantas em uma área restrita.

Na Tabela 2 estão apresentados os resultados da porcentagem de controle de $B$. subquadripara proporcionado por diferentes doses do herbicida diquat e em diversos períodos após a aplicação do herbicida. Podese observar que, como para a espécie anterior, já no primeiro DAA todas as plantas de $B$. subquadripara submetidas à ação do herbicida diquat apresentaram sintomas de intoxicação, independentemente da dose aplicada.

Aos 2 DAA os sintomas de intoxicação nas plantas evoluíram, mas não atingiram níveis ainda satisfatórios para um bom controle, com no máximo $77,8 \%$. Já aos 4 DAA os tratamentos com diquat apresentaram ligeiro aumento em sua eficiência de controle das plantas de tanner-grass, com exceção da aplicação da dose única de $960 \mathrm{~g}$. As médias de controle variaram de 71,1 a $80,7 \%$, corroborando Carbonari et al. (2003), que, ao avaliarem o controle dessa mesma espécie com diquat, em caixas-d'água, observaram porcentagens de controle de até $81 \%$ com aplicação de 400 g i.a. ha ${ }^{1}$, também aos 4 DAA.

Aos 7 DAA foi verificado que grande quantidade de rebrotas surgiu em todos os tratamentos com diquat, reduzindo assim os niveis de controle proporcionados pelo herbicida 
Tabela 1 - Porcentagem de controle de Eichhornia crassipes em diferentes períodos de tempo após a aplicação do herbicida diquat. Americana-SP, 2005

\begin{tabular}{|c|c|c|c|c|c|c|c|c|c|}
\hline \multirow{2}{*}{ Tratamento } & \multirow{2}{*}{$\begin{array}{c}\text { Dose } \\
\left(\mathrm{g} \text { i.a. } \mathrm{ha}^{-1}\right)\end{array}$} & \multicolumn{8}{|c|}{ Dias após a aplicação } \\
\hline & & 1 & 2 & 4 & 7 & 14 & $2^{3 /}$ & 21 & 28 \\
\hline 1. testemunha & - & $00,0 \mathrm{c}$ & $00,0 \mathrm{~b}$ & $00,0 \mathrm{~b}$ & $00,0 \mathrm{~b}$ & $00,0 \mathrm{c}$ & $00,0 \mathrm{c}$ & $00,0 \mathrm{c}$ & $00,0 \mathrm{~b}$ \\
\hline 2. diquat ${ }^{1 /}$ & $480+480^{2 \prime}$ & $37,14 \mathrm{a}$ & $55,0 \mathrm{a}$ & $83,8 \mathrm{a}$ & $83,0 \mathrm{a}$ & $89,4 \mathrm{ab}$ & $97,3 \mathrm{a}$ & $97,7 \mathrm{a}$ & $98,4 \mathrm{a}$ \\
\hline 3. diquat ${ }^{1 /}$ & 960 & $26,42 \mathrm{~b}$ & $57,1 \mathrm{a}$ & $86,7 \mathrm{a}$ & $83,7 \mathrm{a}$ & $87,8 \mathrm{~b}$ & $88,1 \mathrm{~b}$ & $94,3 \mathrm{~b}$ & $97,7 \mathrm{a}$ \\
\hline 4. diquat ${ }^{1 /}$ & $960+960^{2}$ & $27,85 \mathrm{~b}$ & $57,8 \mathrm{a}$ & $85,8 \mathrm{a}$ & $85,1 \mathrm{a}$ & $92,3 \mathrm{a}$ & $97,8 \mathrm{a}$ & $97,7 \mathrm{a}$ & $97,7 \mathrm{a}$ \\
\hline F tratamento & & $59,327 * *$ & $573,2112^{* *}$ & $1.921,74 * *$ & $2.052,52 * *$ & $1.230,74 * *$ & $4.437,62^{* *}$ & $2.358,18^{* *}$ & $21.699,7^{* *}$ \\
\hline $\mathrm{CV}(\%)$ & & 24,0 & 7,4 & 4,0 & 3,9 & 5,0 & 2,7 & 3,6 & 1,2 \\
\hline d.m.s & & 6,05 & 3,46 & 2,84 & 2,70 & 3,74 & 2,08 & 2,90 & 0,97 \\
\hline
\end{tabular}

${ }^{1 /}$ produto comercial Reward. ${ }^{2 /}$ segunda aplicação da mesma dose. ${ }^{3 /}$ dias após a segunda aplicação de diquat. Medias seguidas de mesma letra na coluna não diferem estatisticamente entre si pelo teste $t(p<0,01)$

Tabela 2 - Porcentagem de controle de Brachiaria subquadripara em diferentes períodos de tempo após a aplicação do herbicida diquat. Americana-SP, 2005

\begin{tabular}{|c|c|c|c|c|c|c|c|c|c|}
\hline \multirow{2}{*}{ Tratamento } & \multirow{2}{*}{$\begin{array}{c}\text { Dose } \\
\left(\mathrm{g} \text { i.a. } \mathrm{ha}^{-1}\right)\end{array}$} & \multicolumn{8}{|c|}{ Dias após a aplicação } \\
\hline & & 1 & 2 & 4 & 7 & 14 & $2^{\frac{3 /}{}}$ & 21 & 28 \\
\hline 1. testemunha & - & $00,0 \mathrm{~b}$ & $00,0 \mathrm{c}$ & $00,0 \mathrm{c}$ & $00,0 \mathrm{c}$ & $00,0 \mathrm{c}$ & $00,0 \mathrm{~d}$ & $00,0 \mathrm{c}$ & $00,0 \mathrm{c}$ \\
\hline 2. diquat ${ }^{1 /}$ & $480+480^{2 !}$ & $38,6 \mathrm{a}$ & $68,6 \mathrm{~b}$ & $71,7 \mathrm{~b}$ & $49,3 \mathrm{~b}$ & $17,8 \mathrm{~b}$ & $82,0 \mathrm{~b}$ & $57,14 \mathrm{a}$ & $20,71 \mathrm{a}$ \\
\hline 3. diquat ${ }^{1 /}$ & 960 & $42,1 \mathrm{a}$ & $77,8 \mathrm{a}$ & $71,1 \mathrm{~b}$ & $57,8 \mathrm{a}$ & $20,0 \mathrm{ab}$ & $20,71 \mathrm{c}$ & $20,71 \mathrm{~b}$ & $15,28 \mathrm{ab}$ \\
\hline 4. diquat ${ }^{1 /}$ & $960+960^{2}$ & $46,4 \mathrm{a}$ & $67,1 \mathrm{~b}$ & $80,7 \mathrm{a}$ & 57,1 & $27,85 \mathrm{a}$ & $93,4 \mathrm{a}$ & $64,28 \mathrm{a}$ & $10,71 \mathrm{~b}$ \\
\hline $\mathrm{F}$ tratamento & & $43,741 * *$ & $583,288^{* *}$ & $227,893 * *$ & $159,186^{* *}$ & $15,654 * *$ & $824,443 * *$ & $143,178 * *$ & $10,887 * *$ \\
\hline $\mathrm{CV}(\%)$ & & 27,0 & 7,4 & 11,8 & 14,1 & 47,9 & 8,6 & 18,9 & 60,4 \\
\hline d.m.s & & 9,46 & 4,34 & 7,26 & 6,40 & 8,68 & 4,77 & 7,42 & 7,78 \\
\hline
\end{tabular}

${ }^{1 /}$ produto comercial Reward. ${ }^{2 /}$ segunda aplicação da mesma dose. ${ }^{3 /}$ dias após a segunda aplicação de diquat. Medias seguidas de mesma letra na coluna não diferem estatisticamente entre si pelo teste $\mathrm{t}(\mathrm{p}<0,01)$.

nas avaliações anteriores. Também, aos 14 DAA, nota-se que o efeito fitotóxico gerado pelo herbicida nas plantas de $B$. subquadripara continuou a diminuir, reduzindo assim as porcentagens de controle em todos os tratamentos químicos testados.

$\mathrm{Na}$ avaliação realizada aos 17 DAA ou 2 DAA para os tratamentos que receberam a segunda aplicação (sequencial), registra-se que o tratamento com aplicação única de $4 \mathrm{~L}$ p.c. ha $\mathrm{ha}^{-1}$ continuou a apresentar potencial de controle reduzido, e nos dois tratamentos que receberam a reaplicação da dose os niveis de controle foram incrementados, tornandose de bons a excelentes, com destaque para o tratamento com dose de $960+960 \mathrm{~g} \mathrm{ha}^{-1}$, que apresentou média de controle de 93,4\%; contudo, aos 21 DAA os dois melhores tratamentos apresentaram-se novamente reduzidos, devido ao reaparecimento de rebrotas como também foi observado aos 28 DAA, quando todos os tratamentos com diquat mostraram-se ineficientes, agora com médias de controle abaixo de 21\%. Esses resultados são muito semelhantes aos obtidos por Carbonari et al. (2003), que também observaram grandes reduções no potencial de controle do herbicida diquat sob plantas de $B$. subquadripara com o passar dos dias da aplicação, até o nível de $23 \%$ de controle aos 37 DAA.

Portanto, a reaplicação na dose de $960+$ $960 \mathrm{~g}$ faz-se necessária para manter niveis de controle considerados de satisfatórios a bons. A redução da massa de tanner-grass pode minimizar os seus efeitos sobre áreas de recreação, bem como proporciona aberturas de canais de navegação e reduz perdas d'água do corpo hídrico.

Ressalta-se que o herbicida diquat, produto comercial Reward, foi testado em reservatório fechado na região de Marília-SP para o controle de plantas imersas, situação esta em que foi determinada a meia-vida em condições naturais: bióticas (ação de microrganismo) e abióticas (ex.: hidrólise, fotólise e estabilidade térmica). Determinou-se que a meia-vida do 
diquat era de 1,87 dia (44,9 horas) e que a taxa diária de inativação foi de 30,98\% (Velini et al., 2006). Independentemente de sua origem, a rápida inativação é o principal fator envolvido na segurança do uso do diquat em ambientes aquáticos. Na condição em que foi realizado este estudo, apenas $2,45 \%$ do diquat permanescia livre na coluna de água, 10 dias após a aplicação.

Na Figura 1 estão apresentadas as concentrações de diquat em água das diferentes doses dos tratamentos e formas de aplicação em função do tempo de avaliação. Observa-se um nivel de resíduo maior após a segunda aplicação, efetuada 15 dias após a primeira. Esse fato deve-se talvez à maior deposição do produto na água na segunda aplicação, devido à redução do dossel de folhas e morte de plantas provenientes da primeira aplicação, não existindo nesse caso o efeito guarda-chuva em relação à água. A pequena quantidade de diquat encontrada na testemunha, que estava a montante da área aplicada, pode ser decorrente da movimentação da água, que é uma constante nesse reservatório devido a ventos fortes, comuns nessa região. Outro aspecto referese à movimentação da embarcação utilizada nas avaliações (um rebocador/empurrador de plantas), de grande proporção, que pode ter colaborado na contaminação da testemunha nas primeiras avaliações em razão do grande volume de água deslocado, além de uma possivel deriva do equipamento de aplicação, bem como ao fato de a testemunha estar próxima à área tratada: $20 \mathrm{~m}$ a montante. Ressalta-se que, quatro dias após a aplicação inicial das diferentes doses de diquat e sete dias após a segunda aplicação, a concentração do produto encontrava-se abaixo de $1 \mathrm{ppb}$, limite esse dentro dos padrões de segurança para utilização da água para diversos fins.

Assim, o herbicida diquat na menor dose testada (960 g) mostrou-se eficiente no controle de plantas de E. crassipes,

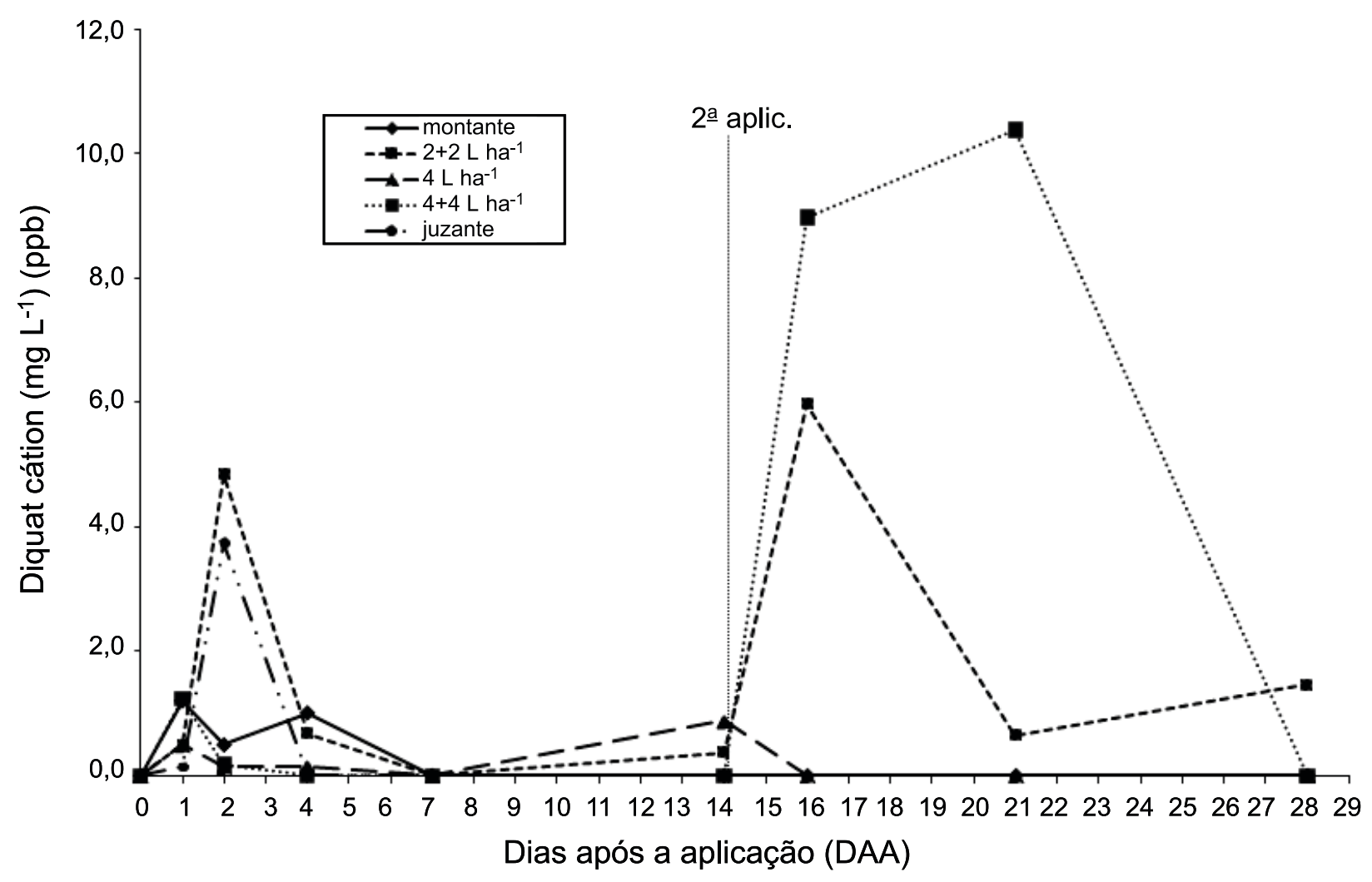

Figura 1 - Concentrações de diquat em água nos diferentes locais e tratamentos estudados, no reservatório de Salto Grande. Americana-SP, 2005. 
independentemente da realização ou não da aplicação sequencial. Já a aplicação de diquat em plantas de $B$. subquadripara mostrou-se eficiente apenas em intervalos curtos de tempo, independentemente da dose testada e do uso ou não da aplicação sequencial.

\section{LITERATURA CITADA}

CAMPOS, C. F. et al. Efeito da chuva sobre a ação do herbicida imazapyr no controle de plantas daninhas aquáticas. Irriga, v. 15, n. 2, p. 151-158, 2010.

CARBONARI, C. A. et al. Controle de Brachiaria subquadripara e Brachiaria mutica através de diferentes herbicidas aplicados em pós-emergência. Planta Daninha, v. 21, p. 79-84, 2003. (Edição Especial)

CARDOSO, L. R. et al. Sensibilidade a herbicidas de acessos de aguapé coletados em reservatórios do Estado de São Paulo. Planta Daninha, v. 21, p. 61-67, 2003. (Edição Especial)

CARVALHO, F. T. et al. Plantas aquáticas e nível de infestação das espécies presentes no reservatório de Bariri, no rio Tietê. Planta Daninha, v. 23, n. 2, p. 371-374, 2005.

CAVENAGHI, A. L. et al. Monitoramento de problemas com plantas aquáticas e caracterização da qualidade de água e sedimento na UHE Mogi-Guaçu. Planta Daninha, v. 23, n. 2, p. 225-231, 2005.

DOMINGOS, V. D. Crescimento de Brachiaria subquadripara (Trin.) Hitch. sob diferentes condições nutricionais e monitoramento sazonal de fatores ambientais no habitat natural. 2007. $172 \mathrm{f}$. Tese (Doutorado em Produção Vegetal) - Universidade Estadual Paulista, Faculdade de Ciências Agronômicas, Botucatu, 2007.

KISSMANN, K. G. Plantas infestantes e nocivas. 2.ed. São Paulo: BASF, 1997. Tomo I. 824 p.

LAVORENTI, A. Comportamento dos herbicidas no meio ambiente. In: WORKSHOP EM BIODEGRADAÇÃO E BIORREMEDIAÇÃO, 3., 1996, Campinas. Anais... Jaguariúna: Embrapa-CNPMA, 1996. p. 81-92.

LORENZI, H. Plantas daninhas do Brasil: terrestres, aquáticas, parasitas e tóxicas. 3.ed. Nova Odessa: Plantarum, 2000. 608 p.

MARCHI, S. R. et al. Efeito de pontas de pulverização e de arranjos populacionais de plantas de Eichhornia crassipes e Salvinia auriculata na deposição de calda de pulverização sobre plantas de Pistia stratiotes. Planta Daninha, v. 27 , n. 2, p. 389-396, 2009.
MARTINS, D. et al. Controle químico de Pistia stratiotes, Eichornia crassipes e Salvini molesta em caixa-d'água. Planta Daninha, v. 20, p. 83-88, 2002. (Edição Especial)

MARTINS, D. et al. Ocorrência de plantas aquáticas nos reservatórios da Light-RJ. Planta Daninha, v. 21, p. 105-108, 2003. (Edição Especial)

MARTINS, D. et al. Caracterização da comunidade de plantas aquáticas de dezoito reservatórios pertencentes a cinco bacias hidrográficas do Estado de São Paulo. Planta Daninha, v. 26, n. 1, p. 17-32, 2008

MARTINS, D. et al. Levantamento da infestação de plantas aquáticas em Porto Primavera antes do enchimento final do reservatório. Planta Daninha, v. 27, p. 879-886, 2009. (Edição Especial)

NEVES, T. et al. Controle químico do aguapé (Eichhornia crassipes). Planta Daninha, v. 20, p. 89-97, 2002. (Edição Especial)

PERAZZA, M. C. et al. O aguapé: meios de controle e possibilidades de utilização. R. DAE, n. 125, p. 18-24, 1985

PITELLI, R. A. Macrófitas aquáticas no Brasil, na condição de problemática. In: WORKSHOP - CONTROLE DE PLANTAS AQUÁTICAS, 1., 1998, Brasília. Resumos... Brasília: IBAMA, 1998. p. 12-15.

ROCHE, R. et al. Características morfológicas indispensables para la classificacion de espécies del gênero Brachiaria. Pastos Forrages, v. 13, n. 3, p. 205-222, 1990.

RODRIGUES, B. N.; ALMEIDA, F. S. Guia de herbicidas. 5.ed. Londrina: 2005. 592 p.

SOCIEDADE BRASILEIRA DA CIÊNCIA DAS PLANTAS DANINHAS - SBCPD. Procedimentos para instalação, avaliação e análise de experimentos com herbicidas. Londrina: 1995. 42 p.

SWARBRICK, J. T. Weeds of Australia, Salviniaceae, Primulaceae, Pontederiaceae. Austr. Weeds, v. 1, n. 10, p. $21-27,1981$

TANAKA, R. H. et al. Ocorrência de plantas aquáticas nos reservatórios da Companhia Energética de São Paulo. Planta Daninha, v. 20, p. 101-111, 2002. (Edição Especial)

VELINI, E. D. et al. Avaliação da eficiência de diquat no controle de plantas aquáticas submersas. In: CONGRESSO BRASILEIRO DA CIÊNCIA DAS PLANTAS DANINHAS, 25., 2006, Brasília. Resumos... Brasília: SBCPD, 2006. p. 256 . 